\section{In vitro fertilization}

MRC tests the climate

A set of guidelines that gives qualified approval for researchers to perform experiments on human embryos obtained through in vitro fertilization was issued las week in a statement by the Medical Research Council (MRC). The guidelines are likely to please scientists working in the area, but the British Medical Association (BMA) has expressed concern that they may be too liberal for its members.

The MRC statement, published in the British Medical Journal, states that clearly defined research on embryos which are not intended for return to the uterus is ethically acceptable if it is "directly relevant" to clinical problems. It also allows the deliberate fertilizing of human ova in vitro for specified and approved research projects, as well as the use of fertilized ova left over from therapeutic programmes, provided that informed consent is obtained from both parents.

The guidelines were drawn up by an MRC advisory group under Professor Geoffrey Dawes. They are intended to apply only to MRC-supported scientists, who must in any case obtain specific approval for any proposed experiment from local scientific and ethical committees. Nevertheless, MRC's ideas are likely to be influential as a basis for discussion within the numerous other committees set up to consider the implications of recent developments in the field of human fertilization, such as the British government's Warnock committee (see Nature 29 July, p.408).

The MRC proposals allow in vitro culture of human embryos only up to the implantation stage, a clearly defined phase of development corresponding roughly to the time at which embryonic tissues become distinct from those of the placenta and organs start to form. This stage is reached at 13-14 days after fertilization, considerably older than the 9-day-old embryos that were at the centre of a recent storm after Dr Robert Edwards announced that he had kept and observed "spare" embryos initially produced for reimplantation. The new guidelines also permit experiments on interspecies formation valuable for studying defective sperm but in this case it is recommended that embryos should not be allowed to develop beyond the early cleavage stage. Experiments on techniques for freezing embryos for storage will be allowed provided that embryos are not stored for future unspecified research.

Dr Anne McLaren, director of MRC's Mammalian Development Unit at University College London, and a member of the advisory group that drew up the guidelines, has pointed out that research aimed at increasing the safety and the success rate of "test-tube baby" programmes is concerned with the embryo before implantation; workers in this area should not therefore find the guidelines overly restrictive.

The BMA, while accepting the MRC guidelines as "a valid contribution to the debate", appears to have reservations about how acceptable they will be to its members: a spokeswoman expressed the view that the MRC guidelines "will do nothing to allay public fears'.

The BMA has its own committee under the chairmanship of Professor Peter
Quilliam, seeking to establish guidelines for the medical profession, and is unwilling to make specific comments until the committee has made its report; however, it seems possible that the adoption of the implantation stage as what is in effect a criterion for the start of a human life could be a point of disagreement. In the meantime, BMA members are not banned from involvement in MRC projects. There is clearly a lot of arguing still to be done: in the foreseeable future there are going to be strong reasons for wanting to experiment on embryos considerably beyond the implantation stage.

Tim Beardsley

\title{
Research article triggers dispute on zeolite
}

\section{Washington}

An experimental result published in the 8 April 1982 issue of Nature has set off a legal battle between Union Carbide and Mobil Oil that may involve hundreds of millions of dollars in patent royalties.

The dispute is over synthetic minerals known as zeolites, which have become increasingly valuable as catalysts in the production of chemicals and liquid fuel from coal. The zeolites, which are crystalline aluminosilicates, have large regular pore structures making them highly selective in binding molecules of a desired size.

In 1977, Union Carbide obtained a patent for what it claimed was a novel form of zeolite called "silicaltite". But according to the analysis reported in the

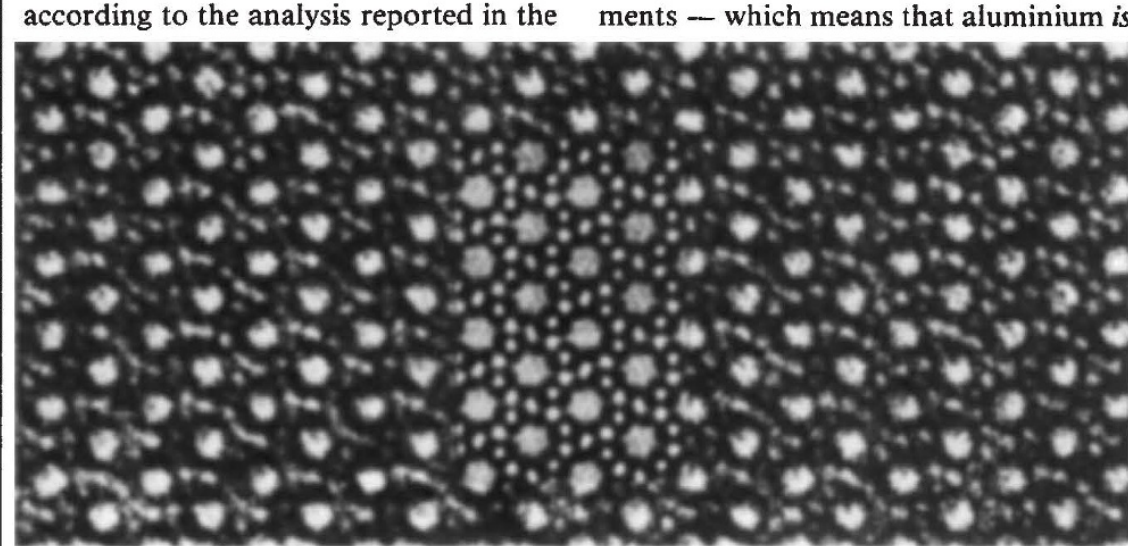

Mobil's ZSM-5 zeolite. The diameter of the largest pores, lined with active sites, is $5.5 \AA$. A computersimulated image is inset. (Photo: G.R. Millward/J.M. Thomas, University of Cambridge.)

Nature article (C.A. Fyfe, J.M. Thomas et al., Nature 296, 530), silicalite is in fact "identical" to a family of zeolites patented by Mobil in 1972. Mobil's zeolites, known as ZSM-5, are vital to Mobil's methanol-to-gasoline process.

Mobil then informed Union Carbide that it considered silicalite an infringement on its patent; Union Carbide responded on 21 September by suing Mobil in the Federal District Court in New York City, asking for a declaratory judgement that silicalite does not infringe on Mobil's patent. In a counterclaim filed 2 weeks ago, Mobil officially entered its charges of infringement.

Neither side is willing to discuss the case in any detail; Mobil has refused even to provide a copy of its response and counterclaim, which are part of the public record. But an industry expert on zeolites gave Nature the following explanation of the facts surrounding the case. Mobil's ZSM-5 patent covers zeolites with silicon-to-aluminium ratios from 10 to 4,000. Union Carbide claims that silicalite is 100 per cent silica within the zeolite framework; any aluminium that happens to be present in silicalite, Union Carbide says, is outside the framework, and thus does not play a part in silicalite's essential properties.

What Fyfe et al. showed, however, is that aluminium is present in silicalite in least two distinct tetrahedral environments - which means that aluminium is in the framework. Aluminium outside the framework is octahedral. "The silicalite structure is shown to be essentially indistinguishable from that of the siliceous zeolite catalyst ZSM-5", Fyfe et al. concluded. Their work involved the use of ${ }^{29} \mathrm{Si}$ and ${ }^{27} \mathrm{Al} \mathrm{NMR}$ spectroscopy.

The speculation is that Union Carbide made the preemptive strike of suing Mobil after receiving an order for silicalite. The threat of a patent infringement suit would have to be removed from Union Carbide and the purchaser before a sale could go through. Union Carbide refuses to say whether an order has been received or whether any silicalite has been sold.

Stephen Budiansky 